\title{
DESEMPENHO DE HÍBRIDOS TRIPLOS DE MILHO OBTIDOS DE TOP CROSSES EM TRÊS LOCAIS DO ESTADO DE SÃO PAULO $\left({ }^{1}\right)$
}

\author{
MARIA ELISA AYRES GUIDETTI ZAGATTO PATERNIANI $\left({ }^{2 *}\right)$; REGINALDO ROBERTO LÜDERS $(2,3)$; \\ AILDSON PEREIRA DUARTE $\left({ }^{4}\right)$; PAULO BOLLER GALLO $\left({ }^{5}\right)$; EDUARDO SAWAZAKI $\left({ }^{2}\right)$
}

\begin{abstract}
RESUMO
Com o objetivo de avaliar a capacidade de combinação e obter híbridos triplos superiores, 30 linhagens do programa de melhoramento de milho do Instituto Agronômico (IAC) foram cruzadas em esquemas top crosses com dois testadores (híbridos simples experimentais). Os 60 híbridos top crosses, os testadores e duas testemunhas foram avaliados em dois ensaios (TC1 e TC2), sob delineamento de blocos casualizados com três repetições, na safra 2001/2002, em Campinas (Centro Experimental do IAC), Mococa (Pólo Regional de Desenvolvimento do Nordeste Paulista/APTA) e Palmital (Pólo Regional de Desenvolvimento do Vale do Paranapanema/APTA). Os seguintes caracteres foram avaliados: altura da planta (AP) e da espiga (AE), plantas acamadas e quebradas (Ac+Que), massa de espigas (ME) e massa de grãos corrigida para $14 \%$ de umidade (MG). A capacidade de combinação foi estimada apenas para $\mathrm{MG}$, de acordo com o Método 2 de Griffing. Pelos resultados constatou-se que tanto os efeitos da Capacidade Geral de Combinação (CGC) como os da Capacidade Específica de Combinação (CEC) foram importantes nesse dialelo. As linhagens que se destacaram quanto à CGC para MG nos três locais foram: L 126, L 111, IP 330 e SLP 103, podendo ser utilizadas para síntese de populações-base em programas de seleção recorrente e para programas de híbridos. Algumas linhagens tiveram elevadas estimativas de $g_{i}$ em locais específicos, como L 3 e L 161 em Palmital; IP 4035 em Mococa e AL 326 e L 14 em Campinas. Visando maximizar o rendimento potencial dos híbridos em cada ambiente, a escolha das linhagens poderá ser feita de acordo com a capacidade de combinação dentro de cada local.
\end{abstract}

Palavras-chave: Zea mays, capacidade combinatória, top cross, híbridos triplos.

\section{ABSTRACT \\ PERFORMANCE OF MAIZE TRIPLE CROSS-WAY HYBRIDS IN THREE ENVIRONMENTS IN SÃO PAULO STATE, BRAZIL}

The objectives of this investigation were to study the combining ability of 30 lines of the maize breeding program of the Instituto Agronomico, São Paulo State, Brazil, in top crosses squemes, aiming at to identify lines for developing high yield triple cross hybrids with two testers (single cross hybrids). The 60 top crosses along with two checks were evaluated in 2001/2002, in two experiments, named TC1 and TC2, following a randomized complete block design with three replicates, over three locations:

( $\left.{ }^{1}\right)$ Recebido para publicação em 27 de outubro de 2005 e aceito em 14 de agosto de 2006.

$\left({ }^{2}\right)$ Centro de Análise e Pesquisa Tecnológica do Agronegócio de Grãos e Fibras, Instituto Agronômico (IAC), Av. Barão de Itapura, n.1481, 13020-902 Campinas (SP). E-mail: elisa@iac.sp.gov.br, ${ }^{*}$ Autora correspondente; sawazaki@iac.sp.gov.br, rrluders@iac.sp.gov.br.

$\left({ }^{3}\right)$ Bolsista da FAPESP.

(4) Pólo Regional de Desenvolvimento do Médio Paranapanema (APTA), Caixa Postal 263, 19800-000, Assis (SP). E-mail: aildson@femanet.com.br.

$\left({ }^{5}\right)$ Pólo Regional de Desenvolvimento do Nordeste Paulista (APTA), Caixa Postal 58, 13730-970, Mococa (SP). E-mail: polonordestepaulista@aptaregional.sp.gov.br . 
Campinas (Centro Experimental Central), Mococa (Pólo Regional de Desenvolvimento do Nordeste Paulista/APTA) e Palmital (Pólo Regional de Desenvolvimento do Vale do Paranapanema/APTA). The traits evaluated were: Plant height (AP) and ear height (AE), percentage of lodged and broken plants (Ac + Que), ear yield (PE) and grain yield corrected to 14\% moisture (PG). The combining ability of the lines to PG was estimated according to Griffing's Method 2. The results showed that both effects CGC and CEC were important in the 2 x 30 diallel. The lines L 126, L 111, SLP 103 and IP 330 were outstanding as to the combining ability for PG in the three locations, being usefull for synthesis of base population in recurrent selection programs or for hybrid programs for broad adaptation. On the other hand, some lines showed high gi estimates in specific locations, such as L 3 and L 161 in Palmital; IP 4035 in Mococa, AL 326 and L 14 in Campinas. Thus, to maximize the hybrid yield potential for each location, the choice of lines must be made with CGC effects within each location.

Key words: combining ability, top cross, triple cross-way hybrids.

\section{INTRODUÇÃO}

O vigor de híbrido representa, sem dúvida, uma das maiores contribuições práticas da Genética à agricultura mundial. O conceito de heterose, definido há mais de um século, continua sendo aplicado principalmente na cultura do milho, onde a produção de híbridos se desenvolveu de maneira ímpar e vem dominando o mercado de sementes. O desempenho de um híbrido é resultado da capacidade de combinação das linhagens envolvidas nos cruzamentos. A capacidade geral de combinação (CGC) é associada principalmente a efeitos aditivos dos genes, enquanto a capacidade específica de combinação (CEC) é determinada por efeitos de dominância e epistasia (Sprague e TATUm, 1942).

Um dos grandes problemas enfrentados pelos melhoristas de milho que trabalham com híbridos de linhagens foi e continua sendo a avaliação das linhagens genitoras quanto à capacidade de combinação. Na prática, os dialélicos completos limitam o número de linhagens a serem utilizadas, requerendo muito esforço nas polinizações manuais para obtenção de todos os cruzamentos desejados. Para contornar o problema, melhoristas têm optado pelo método de top crosses proposto por Davis (1924) para testar linhagens em programas de milho híbrido, o qual consiste em avaliar o mérito relativo de um grande número de linhagens em cruzamentos com testadores, eliminando as de desempenho agronômico inferior, tornando mais racional e eficiente o programa de híbridos (Nurmberg et al., 2000).

Segundo Miranda Filho e Viégas (1987) a utilização de híbrido simples como testador é um processo muito empregado, pois permite avaliar um número grande de linhagens, fornece informações de uso mais imediato e possibilita a obtenção de híbridos triplos superiores.

A interação genótipo por ambiente é um fator de extrema importância e uma expressiva fonte de variação em ensaios de híbridos de milho. Há evidências de que a variância das estimativas de CGC e CEC podem interagir com locais e anos e que a CEC inclui desvios de dominância e epistasia, além de uma porção significativa da interação genótipo por ambiente (Rojas e Sprague, 1952). Sprague e Eberhart (1977) recomendam duas repetições por local e três a cinco ambientes para avaliações de cruzamentos de milho, porque a interação de efeitos aditivos por ambiente é um fator significativo na manifestação da variância fenotípica. O aumento no número de ambientes reduz o erro e a interação de efeitos aditivos por ambiente, enquanto o aumento no número de repetições somente reduz a contribuição do erro na variância fenotípica (EBERHART et al., 1995).

O presente trabalho pretende avaliar o desempenho dos híbridos triplos de milho e estimar a capacidade combinatória das linhagens em esquemas top crosses, em três locais de condições climáticas e edáficas distintas do Estado de São Paulo.

\section{MATERIAL E MÉTODOS}

Trinta linhagens, listadas na tabela 1, provenientes de germoplasma de clima temperado (CIMMYT) e tropical (do programa de melhoramento de milho do IAC) foram cruzadas em esquemas top crosses com dois testadores de base genética restrita (IAC 21 e IAC 101.121). Os 60 híbridos (híbridos simples) resultantes juntamente com as testemunhas comerciais (AGN 2012 e BR 3123) foram avaliados em dois ensaios denominados TC 1 e TC 2, em 2001/2002, no Centro Experimental Central, em Campinas (latitude $22^{\circ} 54^{\prime} \mathrm{S}$ longitude $47^{\circ} 3^{\prime} \mathrm{W}$ e altitude de 600 m); nas Unidades de Pesquisa da Agência Paulista de Tecnologia dos Agronegócios de Mococa (latitude $21^{\circ}$ $28^{\prime} \mathrm{S}$ longitude $47^{\circ} 01^{\prime} \mathrm{W}$ e altitude $665 \mathrm{~m}$ ) (em) e de Palmital (latitude $22^{\circ} 48^{\prime} \mathrm{S}$ longitude $50^{\circ} 14^{\prime} \mathrm{W}$ e altitude $501 \mathrm{~m}$ ). Os solos de Campinas, Mococa e 
Palmital foram caracterizados, respectivamente, como Latossolo, Argissolo e Latossolo Vermelho distroférrico. O delineamento experimental utilizado foi o de blocos ao acaso com três repetições, nos três locais. Cada parcela foi constituída de duas linhas de $5 \mathrm{~m}$ espaçadas de $0,90 \mathrm{~m}$ entre linhas $(0,80 \mathrm{~m}$ em Palmital) e 0,20 m entre plantas. As datas de plantio foram $10 / 11 / 01,20 / 11 / 02$ e 5/11/01 e de colheita 15/4/02, 5/5/02 e 8/3/02, respectivamente, em Campinas, Mococa e Palmital. Para adubação de plantio e cobertura utilizou-se a fórmula 8-28-16 na dose $250 \mathrm{~kg} \mathrm{ha}^{-1}$ e $150 \mathrm{~kg}$ de sulfato de amônio em Campinas; $400 \mathrm{~kg}$ ha-1 da fórmula 8-28-16 e $200 \mathrm{~kg}$ $\mathrm{ha}^{-1}$ de 20-05-20 em Mococa; $300 \mathrm{~kg}$ ha- $^{1}$ 8-28-16 + Zn e $100 \mathrm{~kg} \mathrm{ha}^{-1}$ de sulfato de amônio em Palmital.
Os caracteres avaliados foram: florescimento masculino (FM); altura da planta (AP); altura da espiga (AE); porcentagem de plantas acamadas e quebradas (Ac+Que); massa de espigas (ME) e massa de grãos corrigida para $14 \%$ de umidade (MG).

Efetuaram-se análises de variância individuais e conjunta e utilizou-se o teste de Tukey a 5\% para comparações de médias. Para análise genética e obtenção das estimativas da capacidade geral de combinação das linhagens, utilizou-se apenas a massa de grãos, considerou-se o dialélico parcial 2 x 30 e adotou-se a adaptação do Método 4 do modelo de Griffing (1956) para dialélico parcial descrito por Cruz e Regazzi (1994), utilizando-se o programa Genes (CRUZ,1997).

Tabela 1. Linhagens de milho utilizadas nos cruzamentos top crosses

\begin{tabular}{|c|c|c|c|c|c|}
\hline n. ${ }^{\circ}$ & Denominação & Procedência & Origem & Tipo de grão & Cor do grão \\
\hline 1 & L 3 & CIMMYT & Pop. 24 & Semiduro & Amarelo \\
\hline 2 & L 4 & CIMMYT & Pop. 24 & Dentado & Amarelo \\
\hline 3 & L 5 & CIMMYT & Pop. 26 & Duro & Laranja \\
\hline 4 & L 6 & CIMMYT & Pop. 26 & Duro & Laranja \\
\hline 5 & L 8 & CIMMYT & Pop. 28 & Dentado & Amarelo \\
\hline 6 & L 9 & CIMMYT & Pop. 36 & Dentado & Laranja \\
\hline 7 & L 10 & CIMMYT & Pop. 36 & Dentado & Amarelo \\
\hline 8 & L 13 & CIMMYT & Pop. 26 & Duro & Laranja \\
\hline 9 & L 14 & CIMMYT & Pop. 27 & Duro & Laranja \\
\hline 10 & L 15 & CIMMYT & Pop. 27 & Dentado & Amarelo \\
\hline 11 & L 111 & CIMMYT & Pop. 26 & Duro & Laranja \\
\hline 12 & L 117 & CIMMYT & Pop. 24 & Dentado & Amarelo \\
\hline 13 & L 126 & CIMMYT & Pop. 27 & Semidentado & Amarelo \\
\hline 14 & L 130 & CIMMYT & Across 7543 & Semiduro & Laranja \\
\hline 15 & L 156 & CIMMYT & Pop. 36 & Semidentado & Laranja \\
\hline 16 & L 160 & CIMMYT & Pop. 28 & Dentado & Amarelo \\
\hline 17 & L 161 & CIMMYT & Pop. 26 & Semiduro & Laranja \\
\hline 18 & L 162 & CIMMYT & Pop. 26 & Dentado & Amarelo \\
\hline 19 & L 168 & CIMMYT & Pop. 24 & Semidentado & Amarelo \\
\hline 20 & L 169 & CIMMYT & Pop. 26 & Dentado & Amarelo \\
\hline 21 & L 170 & CIMMYT & Pop. 27 & Duro & Laranja \\
\hline 22 & L 171 & CIMMYT & Pop. 28 & Dentado & Amarelo \\
\hline 23 & AL 218 & IAC & Cateto & Duro & Laranja \\
\hline 24 & AL 326 & IAC & Cateto & Duro & Laranja \\
\hline 25 & AL 11 & IAC & Cateto & Duro & Laranja \\
\hline 26 & AL 628 & IAC & Cateto & Duro & Laranja \\
\hline 27 & IP 330 & IAC & Tuxpeno & Dentado & Amarelo \\
\hline 28 & SLP 103 & IAC & San Louis Potossy & Duro & Laranja \\
\hline 29 & IP 701 & IAC & Tuxpeno & Dentado & Amarelo \\
\hline 30 & IP 4035 & IAC & Tuxpeno & Dentado & Amarelo \\
\hline
\end{tabular}




\section{RESULTADOS E DISCUSSÃO}

Na análise de variância do TC 1, houve efeitos significativos $(\mathrm{P}<0,01)$ de locais e híbridos para todos os caracteres avaliados. O efeito da interação híbrido $x$ local $(\mathrm{H} \times \mathrm{L})$ foi significativo $(\mathrm{P}<0,01)$ para $\mathrm{FM}, \mathrm{Ac}+\mathrm{Que}, \mathrm{ME}$ e MG. Já para o TC 2, foram detectados efeitos de híbridos significativos $(\mathrm{P}<0,01)$ para todos os caracteres, mas $\mathrm{O}$ efeito de locais foi significativo para FM, Ac+Que, ME e
MG. O efeito da interação foi significativo a $(\mathrm{P}<0,01)$ apenas para FM e para ME e MG $(\mathrm{P}<0,05)$.

A média de MG dos cruzamentos nos três locais variou de 6.744 a $8.654 \mathrm{~kg} \mathrm{ha}^{-1}$ no TC 1 e de 7.123 a $8.845 \mathrm{~kg} \mathrm{ha}^{-1}$ no TC 2 . Os híbridos em geral foram precoces, observando-se valores de altura da planta e da espiga inferiores aos dos híbridos comerciais, principalmente em cruzamentos com linhagens de germoplasma temperado ( Tabelas 2 e 3 ).

Tabela 2. Médias de florescimento masculino (FM), altura de planta (AP), altura de espiga (AE), porcentagem de plantas acamadas+quebradas (Ac+Que), massa de espigas (ME) e massa de grãos (MG) corrigida para 14,0\% de umidade, de 30 híbridos triplos experimentais do top cross 1, das testemunhas e do testador 1. Campinas, Mococa e Palmital (SP), safra $2001 / 2002$

\begin{tabular}{|c|c|c|c|c|c|c|}
\hline Híbridos triplos & FM & $\mathrm{AP}$ & $\mathrm{AE}$ & Ac+Que & $\mathrm{ME}$ & MG \\
\hline & dias & \multicolumn{2}{|c|}{$\mathrm{cm}$} & $\%$ & \multicolumn{2}{|c|}{$\mathrm{kg} \mathrm{ha}^{-1}$} \\
\hline IAC $21 \times$ L 3 & 58,44 & 228 & 132 & 4,66 & 10577 & 8133 \\
\hline IAC $21 \times$ L 4 & 59,22 & 236 & 130 & 5,40 & 10362 & 7916 \\
\hline IAC $21 \times$ L 5 & 56,33 & 249 & 136 & 4,14 & 9855 & 7647 \\
\hline IAC $21 \times$ L 6 & 55,78 & 231 & 132 & 4,74 & 10137 & 8061 \\
\hline IAC $21 \times$ L 8 & 58,44 & 218 & 116 & 4,62 & 8678 & 6845 \\
\hline IAC 21 x L 9 & 56,78 & 216 & 120 & 4,50 & 8860 & 7143 \\
\hline IAC $21 \times$ L 10 & 56,22 & 214 & 108 & 3,00 & 9517 & 8019 \\
\hline IAC $21 \times$ L 13 & 55,89 & 223 & 115 & 3,67 & 9447 & 7517 \\
\hline IAC $21 \times$ L 14 & 59,56 & 243 & 135 & 5,36 & 10255 & 7734 \\
\hline IAC $21 \times$ L 15 & 58,33 & 252 & 138 & 4,85 & 9275 & 7172 \\
\hline IAC $21 \times$ L 111 & 56,33 & 247 & 131 & 5,11 & 10473 & 8331 \\
\hline IAC $21 \times$ L 117 & 58,67 & 235 & 120 & 2,57 & 9873 & 7568 \\
\hline IAC $21 \times$ L 126 & 57,44 & 245 & 142 & 3,38 & 10634 & 8486 \\
\hline IAC $21 \times$ L 130 & 57,67 & 228 & 128 & 4,02 & 10255 & 8161 \\
\hline IAC $21 \times$ L 156 & 56,22 & 239 & 127 & 3,51 & 10815 & 8625 \\
\hline IAC $21 \times$ L 160 & 55,89 & 231 & 129 & 4,41 & 9286 & 7428 \\
\hline IAC 21 x L 161 & 56,22 & 237 & 131 & 4,95 & 9648 & 7679 \\
\hline IAC $21 \times$ L 162 & 56,56 & 233 & 128 & 5,04 & 9429 & 7281 \\
\hline IAC $21 \times$ L 168 & 56,44 & 238 & 133 & 6,79 & 9185 & 7373 \\
\hline IAC $21 \times$ L 169 & 56,33 & 234 & 128 & 5,35 & 9075 & 7240 \\
\hline IAC $21 \times$ L 170 & 57,00 & 226 & 119 & 4,53 & 9155 & 7327 \\
\hline IAC $21 \times$ L 171 & 56,78 & 213 & 120 & 5,68 & 8675 & 6744 \\
\hline IAC $21 \times$ AL 218 & 56,44 & 233 & 129 & 5,20 & 9220 & 7390 \\
\hline IAC $21 \times$ AL 326 & 57,67 & 248 & 136 & 5,21 & 10376 & 8285 \\
\hline IAC $21 \times$ AL 11 & 57,67 & 243 & 134 & 3,96 & 10193 & 8186 \\
\hline IAC $21 \times$ AL 628 & 57,56 & 255 & 155 & 6,49 & 10287 & 8654 \\
\hline IAC $21 \times$ IP 330 & 57,44 & 244 & 141 & 3,63 & 11149 & 8651 \\
\hline IAC $21 \times$ SLP 103 & 59,33 & 251 & 143 & 4,12 & 10778 & 8382 \\
\hline IAC 21 x IP 701 & 58,11 & 248 & 138 & 4,64 & 10425 & 8086 \\
\hline IAC 21 x IP 4035 & 57,56 & 239 & 137 & 5,31 & 10519 & 8340 \\
\hline IAC 21 & 58,00 & 222 & 120 & 4,65 & 9018 & 7247 \\
\hline IAC101.121 & 59,56 & 242 & 145 & 2,20 & 9137 & 7036 \\
\hline AGN 2012 & 58,11 & 227 & 126 & 2,62 & 11145 & 8900 \\
\hline BR 3123 & 58,33 & 237 & 140 & 2,36 & 11824 & 9332 \\
\hline Média & 57,4 & 235,39 & 130,71 & 4,43 & 9927 & 7850 \\
\hline D.m.s (5\%) & 1,55 & 20,84 & 15,71 & 22,08 & 1660 & 1298 \\
\hline C.V. $(\%)$ & 1,49 & 4,88 & 6,62 & 58,51 & 9,22 & 9,11 \\
\hline
\end{tabular}


Tabela 3. Médias de florescimento masculino (FM), altura de planta (AP), altura de espiga (AE) e porcentagem de plantas acamadas+quebradas (Ac+Que), massa de espigas (ME) e massa de grãos (MG) corrigida para 14,0\% de umidade, de 30 híbridos triplos experimentais do top cross 2, das testemunhas e do testador 2. Campinas, Mococa e Palmital (SP), safra 2001/2002

\begin{tabular}{|c|c|c|c|c|c|c|}
\hline Híbridos triplos & FM & $\mathrm{AP}$ & $\mathrm{AE}$ & Ac+Que & $\mathrm{ME}$ & MG \\
\hline & dias & \multicolumn{2}{|c|}{$\mathrm{cm}$} & $\%$ & \multicolumn{2}{|c|}{$\mathrm{kg} \mathrm{ha}^{-1}$} \\
\hline IAC 101.121 x L 3 & 59,56 & 242 & 144 & 2,78 & 10447 & 7948 \\
\hline IAC $101.121 \times$ L 4 & 58,89 & 246 & 141 & 2,86 & 11031 & 8349 \\
\hline IAC 101.121 x L 5 & 57,67 & 248 & 146 & 2,11 & 9910 & 7742 \\
\hline IAC 101.121) x L 6 & 57,11 & 250 & 148 & 3,45 & 9733 & 7602 \\
\hline IAC 101.121 x L 8 & 59,00 & 243 & 145 & 2,86 & 9503 & 7320 \\
\hline IAC 101.121 x L 9 & 58,67 & 234 & 142 & 4,19 & 10635 & 8161 \\
\hline IAC $101.121 \times$ L 10 & 57,00 & 239 & 135 & 2,38 & 10691 & 8845 \\
\hline IAC 101.121 x L 13 & 56,44 & 233 & 134 & 3,12 & 9928 & 7874 \\
\hline IAC $101.121 \times$ L 14 & 59,00 & 261 & 150 & 2,57 & 10202 & 7939 \\
\hline IAC $101.121 \times$ L 15 & 58,56 & 253 & 146 & 2,59 & 10610 & 8183 \\
\hline IAC 101.121 x L 111 & 58,00 & 257 & 149 & 3,66 & 10818 & 8304 \\
\hline IAC 101.121 x L 117 & 59,33 & 246 & 134 & 2,02 & 10084 & 7777 \\
\hline IAC $101.121 \times$ L 126 & 59,89 & 247 & 145 & 2,79 & 10978 & 8656 \\
\hline IAC $101.121 \times$ L 130 & 56,89 & 243 & 144 & 2,34 & 9339 & 7287 \\
\hline IAC 101.121 x L 156 & 56,89 & 241 & 137 & 2,23 & 9826 & 7746 \\
\hline IAC 101.121 x L 160 & 56,33 & 238 & 139 & 3,49 & 10317 & 8441 \\
\hline IAC 101.121 x L 161 & 58,44 & 243 & 146 & 2,28 & 10224 & 8149 \\
\hline IAC 101.121 x L 162 & 56,44 & 229 & 119 & 3,68 & 8711 & 7177 \\
\hline IAC 101.121 x L 168 & 57,56 & 240 & 149 & 3,67 & 9887 & 7619 \\
\hline IAC 101.121 x L 169 & 58,11 & 246 & 150 & 3,07 & 8904 & 7123 \\
\hline IAC 101.121 x L 170 & 57,00 & 239 & 137 & 3,21 & 9482 & 7258 \\
\hline IAC 101.121 x L 171 & 57,44 & 236 & 146 & 2,88 & 9630 & 7363 \\
\hline IAC 101.121 x AL 218 & 57,78 & 261 & 151 & 2,97 & 10489 & 8207 \\
\hline IAC 101.121 x AL 326 & 58,44 & 260 & 154 & 4,60 & 10515 & 7893 \\
\hline IAC 101.121 x AL 11 & 60,67 & 261 & 157 & 3,64 & 10094 & 7798 \\
\hline IAC 101.121 x AL 628 & 60,11 & 272 & 172 & 4,01 & 10026 & 7735 \\
\hline IAC 101.121 x IP 330 & 60,78 & 254 & 148 & 3,58 & 10151 & 7996 \\
\hline IAC 101.121x SLP 103 & 60,56 & 285 & 186 & 2,67 & 10406 & 8195 \\
\hline IAC 101.121 x IP 701 & 60,56 & 256 & 155 & 2,55 & 10047 & 7711 \\
\hline IAC 101.121 x IP 4035 & 60,22 & 267 & 161 & 3,65 & 9671 & 7786 \\
\hline IAC 21 & 57,33 & 225 & 121 & 3,67 & 9258 & 7280 \\
\hline IAC 101.121 & 60,67 & 251 & 153 & 3,48 & 9604 & 7509 \\
\hline AGN 2012 & 57,22 & 233 & 124 & 2,11 & 11180 & 8969 \\
\hline BR 3123 & 59,22 & 241 & 141 & 1,54 & 10804 & 8973 \\
\hline Média & 58,46 & 247,71 & 145,58 & 2,95 & 10092 & 7909 \\
\hline D.m.s (5\%) & 1,82 & 22,10 & 17,93 & 16,20 & 1784 & 1432 \\
\hline C.V. (\%) & 1,72 & 4,92 & 6,79 & 53,0 & 9,74 & 9,99 \\
\hline
\end{tabular}

Destacaram-se com produtividades próximas às das testemunhas comerciais os seguintes híbridos triplos no TC1: IAC $21 \times$ AL 628, IAC $21 \times$ IP 330, IAC $21 \times$ L 156 e IAC $21 \times$ L 126, IAC $21 \times$ SLP 103, IAC 21 X IP 4035 e IAC 21 X L111. No TC2, ressaltaramse: IAC $101.121 \times$ L 10, IAC $101.121 \times$ L 126, IAC 101.121 x L 160, IAC 101.121x L 4, IAC $101.121 \times$ L 111 e IAC 101.121 x SLP 103.
Os híbridos tiveram produtividade relativa diferente nos diferentes locais (interação genótipo x ambiente significativa), por isso os resultados da produtividade de grãos são apresentados por testador e por local (Tabela 4). Esses resultados concordam com os de Gama et al. (2003), que afirmam que híbridos de base genética mais estreita têm maior interação genótipo por ambiente do que germoplasma de base genética mais ampla. 
Tabela 4. Médias de massa de grãos (MG) corrigida para 14,0\% de umidade, de 30 híbridos triplos experimentais dos top crosses 1 (testador IAC 21) e 2 (testador IAC 101.121), das testemunhas e dos testadores em três locais do Estado de São Paulo. Safra 2001/2002

\begin{tabular}{|c|c|c|c|c|c|c|}
\hline \multirow{3}{*}{ Linhagens } & \multicolumn{2}{|c|}{ Campinas } & \multicolumn{2}{|c|}{ Mococa } & \multicolumn{2}{|c|}{ Palmital } \\
\hline & \multicolumn{6}{|c|}{ Testadores } \\
\hline & IAC 21 & IAC101.121 & IAC 21 & IAC101.121 & IAC 21 & IAC101.121 \\
\hline & & & 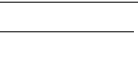 & & & \\
\hline L 3 & 7813 & 6374 & 8392 & 8996 & 8192 & 8474 \\
\hline L 4 & 7962 & 7049 & 7488 & 9778 & 8299 & 8220 \\
\hline L 5 & 7099 & 6514 & 8743 & 8674 & 7098 & 8038 \\
\hline L 6 & 7540 & 6081 & 8450 & 9228 & 8192 & 7496 \\
\hline L 8 & 6244 & 5987 & 7427 & 8238 & 6864 & 7736 \\
\hline L 9 & 6737 & 7242 & 7757 & 9118 & 6934 & 8122 \\
\hline L 10 & 7945 & 7539 & 8234 & 10694 & 7879 & 8302 \\
\hline L 13 & 7016 & 6630 & 8608 & 8535 & 6927 & 8456 \\
\hline L 14 & 7838 & 7406 & 7720 & 8873 & 7642 & 7537 \\
\hline L 15 & 7159 & 7276 & 7024 & 9305 & 7334 & 7967 \\
\hline L 111 & 8380 & 7364 & 9000 & 9362 & 7612 & 8185 \\
\hline L 117 & 7168 & 6946 & 8352 & 8616 & 7183 & 7767 \\
\hline L 126 & 7517 & 7068 & 8739 & 10051 & 9202 & 8850 \\
\hline L 130 & 8258 & 6540 & 8458 & 7920 & 7766 & 7402 \\
\hline L 156 & 7994 & 7394 & 9908 & 8344 & 7972 & 7500 \\
\hline L 160 & 7348 & 7239 & 7761 & 9151 & 7176 & 8934 \\
\hline L 161 & 7459 & 6857 & 7477 & 8759 & 8099 & 8831 \\
\hline L 162 & 7395 & 6116 & 7411 & 7887 & 7038 & 7527 \\
\hline L 168 & 6261 & 6562 & 8116 & 8596 & 7743 & 7699 \\
\hline L 169 & 6404 & 5626 & 8213 & 8124 & 7103 & 7618 \\
\hline L 170 & 6669 & 5974 & 8034 & 8193 & 7277 & 7608 \\
\hline L 171 & 7180 & 6810 & 6714 & 7814 & 6338 & 7466 \\
\hline AL 218 & 6525 & 7534 & 7932 & 8702 & 7713 & 8386 \\
\hline AL 326 & 8122 & 7796 & 8934 & 8352 & 7798 & 7530 \\
\hline AL 11 & 7811 & 7257 & 9207 & 8140 & 7539 & 7997 \\
\hline AL 628 & 7943 & 7050 & 9721 & 8128 & 8300 & 8029 \\
\hline IP 330 & 8366 & 7704 & 9800 & 8059 & 7797 & 8226 \\
\hline SLP 103 & 7460 & 7327 & 8425 & 10030 & 9260 & 7227 \\
\hline IP 701 & 7884 & 6808 & 8295 & 8865 & 8080 & 7460 \\
\hline IP 4035 & 8025 & 6464 & 9480 & 9338 & 7514 & 7555 \\
\hline IAC 21 & 7645 & 6045 & 6828 & 7671 & 7268 & 8124 \\
\hline IAC101.121 & 6667 & 6546 & 7480 & 8063 & 6959 & 7918 \\
\hline AGN 2012 & 8437 & 8370 & 10364 & 10568 & 7899 & 7968 \\
\hline BR 3123 & 9893 & 9115 & 9292 & 9240 & 8811 & 8563 \\
\hline Média & 7534 & 6959 & 8346 & 8806 & 7670 & 7962 \\
\hline D.m.s (5\%) & 2378 & 2331 & 2360 & 2638 & 2281 & 2762 \\
\hline C.V. $(\%)$ & 9,6 & 10,2 & 8,6 & 9,2 & 9,1 & 10,6 \\
\hline
\end{tabular}


Na tabela 5, está apresentado o resumo da análise dialélica $2 \times 30$ para massa de grãos, com efeitos significativos para cruzamentos, ambiente e interação cruzamento $x$ ambiente. $O$ efeito significativo de cruzamentos $(\mathrm{P}<0,01)$ deve-se aos efeitos significativos da CGC do grupo II (linhagens) e da CEC, não havendo efeitos significativos da CGC entre os testadores, provavelmente decorrente de certa similaridade genética entre os testadores, ambos de germoplasma temperado. Pela significância da CGC verifica-se que as linhagens diferiram entre si na freqüência de alelos favoráveis, existindo linhagens com maior possibilidade de formar híbridos mais produtivos.

A CEC significativa indica que alguns híbridos tiveram desempenho superior ou inferior ao previsto pela CGC. A interação cruzamentos x local foi altamente significativa, devida aos efeitos significativos de CGC I x Local e CEC x local, não havendo interação entre os efeitos da CGC II (linhagens) x local. Portanto, a capacidade de combinação relativa das linhagens do Grupo II não se alterou nos diferentes locais, evidenciando-se a interação da capacidade específica (desvios de dominância) x local.

Tabela 5. Resumo da análise de variância conjunta de massa de grãos, do dialelo 2 × 30, em três locais do Estado de São Paulo. Safra 2001/2002

\begin{tabular}{lcc}
\hline Fonte de variação & G.L. & Q.M. \\
\hline Cruzamento & 59 & $2148929,0^{* *}$ \\
CGC I & 1 & 481536,0 \\
CGC II & 29 & $2877298,75^{* *}$ \\
CEC & 29 & $1478055,75^{*}$ \\
Ambiente & 2 & $87661620,42^{* *}$ \\
Cruzamento x Ambiente & 118 & $1002151,67^{* *}$ \\
CGC I X Ambiente & 2 & $13628598,42^{* *}$ \\
CGC II X Ambiente & 58 & 693504,74 \\
CEC X Ambiente & 58 & $875403,89^{* *}$ \\
Erro combinado & 348 & 580189,67 \\
Média Geral & 7843 & \\
\hline
\end{tabular}

*: significativo a $\mathrm{P}<0,05$ pelo Teste $\mathrm{F}$.

**: significativo a $\mathrm{P}<0,01$ pelo Teste $\mathrm{F}$.

Pelos resultados verifica-se que ambos os efeitos, da CGC e da CEC, foram importantes neste dialelo. Os Quadrados Médios referentes à CGC do Grupo II (linhagens) e CEC foram altamente significativos $(\mathrm{P}<0,01)$, o que indica a presença de efeitos aditivos e não-aditivos na variância genotípica destes cruzamentos, para MG. Os efeitos gênicos aditivos e não aditivos corresponderam a $66,06 \%$ e $33,94 \%$, respectivamente. GAMA et al. (1992) verificaram valores de $49 \%$ e $41 \%$, para efeitos aditivos e não aditivos para ME, em dialelo entre populações de milho; Ribeiro et al. (2002) avaliaram o desempenho de populações de milho em cruzamentos dialélicos e obtiveram efeitos aditivos mais pronunciados para as variáveis $\mathrm{FM}, \mathrm{AP}, \mathrm{AE}$ e $\mathrm{MG}$, embora o efeito da interação também tenha sido significativo. NAss et al. (2000) obtiveram contribuições dos efeitos da CGC e CEC de 56 e $44 \%$, para ME, em um dialelo de 10 linhagens, na média de três ambientes.

SAWAZAKI et al. (2002), trabalhando com milho pipoca também notaram valores significativos de CGC e CEC para as variáveis AP, AE e MG, indicando predominância de efeitos aditivos para os três caracteres. GAMA et al. (2003), ao contrário, observaram maiores efeitos da capacidade específica de combinação para ME em um dialelo de linhagens do sintético de milho CMS 53. De acordo com Hallauer e Miranda Filho (1988), efeitos de dominância são mais relevantes para rendimento de grãos do que para outros caracteres de milho.

Os resultados do presente trabalho, de maiores efeitos da capacidade geral de combinação, concordam com PATERniani (2003), sugerindo que linhagens já extensivamente melhoradas em ambientes distintos tenham maior contribuição de efeitos aditivos na manifestação de PE e PG.

Altas estimativas de $\mathrm{g}_{\mathrm{i}}$, em valores absolutos ocorrem, em geral, para genótipos cujas freqüências de alelos são consistentemente maiores ou menores que a freqüência média dos alelos favoráveis em todos os genótipos testados. Tais efeitos são indicativos da importância dos genes predominantemente aditivos em seus efeitos (Sprague e TATUM, 1942).

As linhagens que se destacaram quanto à capacidade combinatória positiva e elevada nos três locais foram: L 126, L 111, IP 330 e SLP 103, podendo ser utilizadas para síntese de populações-base em programas de seleção recorrente e para programas de híbridos visando à adaptação em vários ambientes. Já algumas linhagens tiveram elevadas estimativas de $g_{i}$ em locais específicos, como L 3 e L 161 em Palmital; IP 4035 em Mococa e AL 326 e L 14 em Campinas (Tabela 6). Assim, concordando com NAss et al. (2000), para maximizar o rendimento potencial dos híbridos em cada ambiente, a escolha das linhagens para programas de híbridos poderá ser feita de acordo com a capacidade de combinação dentro de cada local. 
Tabela 6. Estimativas dos efeitos da capacidade de combinação $\left(\mathrm{g}_{\mathrm{i}}\right)$ para massa de grãos de 30 linhagens de milho em três locais do Estado de São Paulo. Safra $2001 / 2002$

\begin{tabular}{|c|c|c|c|}
\hline \multirow[b]{2}{*}{ Linhagens } & \multicolumn{3}{|c|}{$\mathrm{g}_{\mathrm{i}}$} \\
\hline & Campinas & Mococa & Palmital \\
\hline & & $-\mathrm{kg} \mathrm{ha}^{-1}$ & \\
\hline L 3 & $-74,17$ & 132,98 & 532,73 \\
\hline L 4 & 337,83 & 71,98 & 459,23 \\
\hline L 5 & $-361,17$ & 147,48 & $-232,27$ \\
\hline L 6 & $-356,67$ & 277,98 & 43,73 \\
\hline L 8 & $-1052,17$ & $-728,52$ & $-500,27$ \\
\hline L 9 & $-178,17$ & $-123,52$ & $-272,27$ \\
\hline L 10 & 574,33 & 902,98 & 290,23 \\
\hline L 13 & $-344,67$ & 10,98 & $-108,77$ \\
\hline L 14 & 454,33 & $-274,52$ & $-210,77$ \\
\hline L 15 & 49,83 & $-396,52$ & $-149,77$ \\
\hline L 111 & 704,33 & 619,48 & 98,23 \\
\hline L 117 & $-110,17$ & $-77,02$ & $-325,27$ \\
\hline L 126 & 124,83 & 833,98 & 1225,73 \\
\hline L 130 & 231,83 & $-372,02$ & $-216,27$ \\
\hline L 156 & 526,33 & 564,98 & $-64,27$ \\
\hline L 160 & 125,33 & $-105,02$ & 254,73 \\
\hline L 161 & $-9,67$ & $-443,02$ & 664,73 \\
\hline L 162 & $-412,17$ & $-912,02$ & $-517,77$ \\
\hline L 168 & $-756,17$ & $-205,02$ & $-79,27$ \\
\hline L 169 & $-1152,17$ & $-392,52$ & $-439,77$ \\
\hline L 170 & $-846,17$ & $-447,52$ & $-357,77$ \\
\hline L 171 & $-172,67$ & $-1297,02$ & $-898,27$ \\
\hline AL 218 & $-138,17$ & $-244,02$ & 249,23 \\
\hline AL 326 & 791,33 & 82,48 & $-136,27$ \\
\hline AL 11 & 366,83 & 112,48 & $-32,27$ \\
\hline AL 628 & 328,83 & 363,48 & 364,23 \\
\hline IP 330 & 867,33 & 363,49 & 211,23 \\
\hline SLP 103 & 225,83 & 666,48 & 443,23 \\
\hline IP 701 & 178,33 & 18,98 & $-30,27$ \\
\hline IP 4035 & 76,83 & 847,98 & $-265,77$ \\
\hline Erro (Gi) & 290,74 & 295,14 & 310,86 \\
\hline Erro $\left(G j-G j^{\prime}\right)$ & 418,20 & 424,53 & 447,14 \\
\hline
\end{tabular}

\section{CONCLUSÕES}

1) Obtiveram-se 13 híbridos triplos ( $20 \%$ dos híbridos experimentais testados) promissores, em ambos os ensaios top crosses, com elevada produtividade e que não diferiram da média das testemunhas comerciais, indicando elevado potencial das linhagens selecionadas para o programa de híbridos de milho.
2) As melhores combinações híbridas foram: IAC 21x AL 628 e IAC 21 x IP 330 no TC1 e IAC 101.121 x L 10 no TC2, nos três locais.

3) Ambos os testadores discriminaram satisfatoriamente as linhagens e produziram híbridos triplos produtivos, destacando-se o testador IAC 101.121 pelas menores taxas de acamamento e quebramento nos híbridos.

4) Os efeitos da CGC e da CEC foram importantes nos cruzamentos das linhagens com os testadores, com predominância de efeitos aditivos na manifestação de MG.

5) As linhagens que se destacaram quanto à capacidade combinatória $\left(g_{i}\right)$ positiva e elevada nos três locais para MG foram: L 126, L 111, IP 330 e SLP 103, podendo ser utilizadas para síntese de populações-base em programas de seleção recorrente e para programas de híbridos visando à alta produtividade e adaptação em vários ambientes.

\section{AGRADECIMENTOS}

À Fundação de Amparo à Pesquisa do Estado de São Paulo (FAPESP) pelo apoio financeiro ao projeto.

\section{REFERÊNCIAS}

CRUZ, C.D.; REGAZZI, A.J. Modelos biométricos aplicados ao melhoramento genético. Viçosa: UFV, 1994. 380p.

CRUZ, C.D. Aplicativo computacional em Genética e Estatística. Programa Genes. Viçosa: UFV, 1997. 442p.

DAVIS, R.L. Report of the plant breeder. Puerto Rico Agricultural Experimental Station Annual Reporter, Puerto Rico, p.14-15, 1924.

EBERHART, S.A.; SALHUANA, W.; SEVILLA, R.; TABA, S. Principles for tropical maize breeding. Maydica, Bergamo, v. 40, p. 339-355, 1995.

GAMA, E.E.G.; GUIMARÃES, P.E.; MAGNAVACA, R.; PARENTONI, S.N.; PACHECO, C.A.P. Avaliação das capacidades geral e específica de combinação em sete populações de milho da América Latina. Pesquisa Agropecuária Brasileira, Brasília, v.27, n.3, p. 1167-1172, 1992.

GAMA, E.E.G.; MEIRELES, W.F.; GUIMARÃES, P.E.; FERRÃO, R.G.; PARENTONI, S.N.; PACHECO, C.A.P.; SANTOS, M.X.; OLIVEIRA, A.C. Combining ability of inbred lines derived from a yellow flint maize synthetic CMS53. Revista Brasileira de Milho e Sorgo, Sete Lagoas, v.2, n.3, p.97-102, 2003.

GRIFFING, J.B. A generalized treatment of the use of diallel crosses in quantitative inheritance. Heredity, London, v.10, p.31-50, 1956. 
HALLAUER, A.R.; MIRANDA FILHO, J.B. Quantitative Genetics in maize breeding. Ames: Iowa State University Press, 1988.

MIRANDA FILHO, J.B.; VIÉGAS, G.P. Milho híbrido. In: PATERNIANI, E.; VIÉGAS, G.P. (Eds). Melhoramento e produção do milho. 2. ed. Campinas: Fundação Cargill, 1987. v. 1, p.277-326.

NASS, L.L.; LIMA, M.; VENCOVSKY, R; GALLO, P.B. Combining ability of maize inbred lines evaluated in three environments in Brazil. Scientia Agricola, Piracicaba, v.57, n.1, p. 129-134, 2000.

NURMBERG, P.L.;SOUZA, J.C.; RAMALHO, M.A.P.; RIBEIRO, P.H.E. Desempenho de híbridos simples como testadores de linhagens de milho em top crosses. In: CONGRESSO BRASILEIRO DE MELHORAMENTO DE PLANTAS, 1., 2000, Goiânia. Resumos... (CD-Rom)

PATERNIANI, M.E.A.G.Z.; SAWAZAKI, E.; DUDIENAS, C.; GALLO, P.B. Diallel crosses among maize lines with emphasis on resistance to foliar diseases. Genetics and Molecular Biology, Ribeirão Preto, v.23, p. 381-385, 2000.

RIBEIRO, P.H.E.;SOUZA, J.C.; RAMALHO, M.A.P. Desempenho de populações de milho em cruzamento dialélicos avaliados em três estados da região norte do Brasil. In: CONGRESSO NACIONAL DE MILHO E SORGO,24., 2002, Florianópolis. Resumo expandido... Florianópolis, 2002. (CD-Rom)
ROJAS, B.A.; SPRAGUE, G.F. A comparison of variance components in corn yield trials. III. General and specific combining ability and their interaction with location and years. Agronomy Journal, Madison, v.44, p. 462-466, 1952.

SAWAZAKI, E.; GALLO, P.B; CASTRO, J.L. de; PATERNIANI, M.E.A.G.Z.; SILVA, R.M.; LUDERS, R.R. Capacidade combinatória de genótipos locais e híbridos exóticos de milho pipoca avaliados em um dialelo parcial. In: Congresso Nacional de Milho e Sorgo, 24., 2002, Florianópolis. Resumo expandido... Florianópolis, 2002. (CD-Rom)

SPRAGUE, G.F.; TATUM, L.A. General vs. specific combining ability in single crosses of corn. Journal of American Society of Agronomy, Madison, v.34, n.10, p.923-932, 1942.

SPRAGUE, G.F.; EBERHART, S. A. Corn breeding. In: SPRAGUE, W. F. (Ed.). Corn and Corn Improvement. Madison: American Society of Agronomy, 1977. p. 335-336. 